\title{
Sequenced BAC anchored reference genetic map that reconciles the ten individual chromosomes of Brassica rapa
} HyeRan Kim ${ }^{\dagger 1,6}$, Su Ryun Choi ${ }^{\dagger 2}$, Jina Bae ${ }^{2}$, Chang Pyo Hong ${ }^{2}$, Seo Yeon Lee ${ }^{2}$, Md Jamil Hossain², Dan Van Nguyen², Mina Jin³, BeomSeok Park ${ }^{3}$, Jea-Wook Bang ${ }^{4}$, Ian Bancroft ${ }^{5}$ and Yong Pyo Lim*1,2

\begin{abstract}
Address: ${ }^{1}$ Plant Genomics Institute, Chungnam National University, Daejeon, 305-764 Korea, ${ }^{2}$ Department of Horticulture, Chungnam Nationa University, Daejeon, 305-764 Korea, ${ }^{3}$ National Institute of Agricultural Biotechnology, Rural Development Administration, Suwon, $441-707$ Korea, ${ }^{4}$ Department of Biology, Chungnam National University, Daejeon, 305-764 Korea, ${ }^{5}$ Department of Crop Genetics, John Innes Centre, Norwich Research Park, Colney, Norwich NR4 7UH, UK and ${ }^{6}$ Macrogen Inc., Seoul 153-023, Korea

Email: HyeRan Kim - hkim@macrogen.com; Su Ryun Choi - ssrchoi@empal.com; Jina Bae - akira2743@cnu.ac.kr; Chang Pyo Hong - idhcp@cnu.ac.kr; Seo Yeon Lee - phose84@hanmail.net; Md Jamil Hossain - mjamil_71@yahoo.com; Dan Van Nguyen - nvdan100@yahoo.com; Mina Jin - genemina@rda.go.kr; Beom-Seok Park - pbeom@rda.go.kr; Jea-Wook Bang - bangjw@cnu.ac.kr; Ian Bancroft - ian.bancroft@bbsrc.ac.uk; Yong Pyo Lim* - yplim@cnu.ac.kr

* Corresponding author †Equal contributors
\end{abstract}

Published: 15 September 2009

BMC Genomics 2009, 10:432 doi:10.1186/147|-2164-10-432
Received: II July 2008

Accepted: 15 September 2009

This article is available from: http://www.biomedcentral.com/147/-2/64/10/432

(c) $2009 \mathrm{Kim}$ et al; licensee BioMed Central Ltd.

This is an Open Access article distributed under the terms of the Creative Commons Attribution License (http://creativecommons.org/licenses/by/2.0), which permits unrestricted use, distribution, and reproduction in any medium, provided the original work is properly cited.

\begin{abstract}
Background: In view of the immense value of Brassica rapa in the fields of agriculture and molecular biology, the multinational Brassica rapa Genome Sequencing Project (BrGSP) was launched in 2003 by five countries. The developing BrGSP has valuable resources for the community, including a reference genetic map and seed BAC sequences. Although the initial $B$. rapa linkage map served as a reference for the BrGSP, there was ambiguity in reconciling the linkage groups with the ten chromosomes of $B$. rapa. Consequently, the BrGSP assigned each of the linkage groups to the project members as chromosome substitutes for sequencing.

Results: We identified simple sequence repeat (SSR) motifs in the $B$. rapa genome with the sequences of seed BACs used for the BrGSP. By testing 749 amplicons containing SSR motifs, we identified polymorphisms that enabled the anchoring of I88 BACs onto the $B$. rapa reference linkage map consisting of 719 loci in the 10 linkage groups with an average distance of $1.6 \mathrm{cM}$ between adjacent loci. The anchored BAC sequences enabled the identification of 30 blocks of conserved synteny, totaling $534.9 \mathrm{cM}$ in length, between the genomes of $B$. rapa and Arabidopsis thaliana. Most of these were consistent with previously reported duplication and rearrangement events that differentiate these genomes. However, we were able to identify the collinear regions for seven additional previously uncharacterized sections of the $A$ genome. Integration of the linkage map with the $B$. rapa cytogenetic map was accomplished by FISH with probes representing $20 \mathrm{BAC}$ clones, along with probes for rDNA and centromeric repeat sequences. This integration enabled unambiguous alignment and orientation of the maps representing the 10 B. rapa chromosomes.

Conclusion: We developed a second generation reference linkage map for $B$. rapa, which was aligned unambiguously to the $B$. rapa cytogenetic map. Furthermore, using our data, we confirmed and extended the comparative genome analysis between B. rapa and A. thaliana. This work will serve as a basis for integrating the genetic, physical, and chromosome maps of the BrGSP, as well as for studies on polyploidization, speciation, and genome duplication in the genus Brassica.
\end{abstract}




\section{Background}

Brassica is a model system for studying polyploidization and speciation since all the species in this genus have descended from a common hexaploid ancestor [1-6]. In addition, Brassica species share an ancestor with Arabidopsis, implying a similar basic genome, and thereby providing sequence-level colinearity between the two genera, particularly in euchromatic regions [7-9]. This relationship highlights the feasibility of utilizing the accumulated Arabidopsis information for the study of Brassica species. The genus Brassica includes economically important crop taxa with a wide range of morphologies, such as Chinese cabbage, mustard, cabbage, broccoli, oilseed rape, and other leafy vegetables. These taxa are classified into six genome types (AA, $\mathrm{n}=10 ; \mathrm{BB}, \mathrm{n}=8 ; \mathrm{CC}, \mathrm{n}=9$; $\mathrm{AABB}, \mathrm{n}=$ 18; AACC, $\mathrm{n}=19 ; \mathrm{BBCC}, \mathrm{n}=17$ ) according to the six representative species (AA, $B$. rapa; $\mathrm{BB}, B$. nigra; $\mathrm{CC}, B$. oleracea; $\mathrm{AABB}$, B. juncea; AACC, B. napus; BBCC, B. carinata), and the genomic relationships of these taxa are well defined in U's triangle [10].

In view of the enomous value of Brassica in the fields of agriculture and molecular biology, genome sequencing projects have been proposed for each of the three diploid genomes [11]. In order to better understand the A genome of Brassica and to take advantage of the colinearity between this genome and the Arabidopsis genome sequence, the multinational Brassica rapa Genome Sequencing Project (BrGSP) was launched in 2003 by scientists from five countries (Korea, Canada, the United Kingdom, China, and Australia) for sequencing B. rapa ssp. pekinensis cv. Chiifu-401-42 using a BAC-by-BAC approach [11]. The initial objective of the BrGSP was to sequence the gene space of $B$. rapa, which represents approximately $330 \mathrm{Mb}$ of its genome [12], at a Phase II quality level, whereby BACs would be sequenced to a single ordered and oriented contig, but with allowance for some gaps and ambiguous bases [13]. The Korean group of the BrGSP [Korean Brassica Genome Project (KBGP)] sequenced 521 B. rapa BACs selected to represent genomic regions collinear with the majority of the euchromatic regions of the $A$. thaliana genome [12]. These clones serve as "seed" BACs for the BrGSP, from which chromosomescale sequencing is being initiated. The developing BrGSP has valuable resources for the community, including three BAC libraries [2,14], 200,017 BAC end sequences [15], 129,928 EST sequences (by April 2008), and an initialversion reference genetic map [16]. To date, 631 BAC sequences, representing approximately $75.3 \mathrm{Mb}$, have been made public [13].

The initial reference linkage map of $B$. rapa was constructed with 556 markers (278 AFLPs; 235 SSRs; 25 RAPDs; and a total of 18 ESTPs, STSs, and CAPSs) based on 78 doubled haploid lines ( $\mathrm{CKDH}$ line) derived from an anther culture of the $\mathrm{F}_{1}$ of a cross between diverse Chinese cabbage (B. rapa ssp. pekinensis) inbred lines; "Chiifu401-42" (C) and "Kenshin-402-43" (K) [16]. Ten linkage groups, designated as A1-A10 according to the common nomenclature of the $B$. napus reference linkage maps [17], served as a reference for the BrGSP. However, there remained ambiguity in reconciling the linkage groups with the $10 \mathrm{~B}$. rapa chromosomes characterized using cytogenetic approaches.

The B. rapa chromosomes have been extensively studied by karyotyping based on morphometric measurements of mitotic metaphase chromosomes [18-21]. The definitive identification of each of the individual chromosomes has been problematic because some are small-sized or similar. Recently, using fluorescence in situ hybridization (FISH), six of the 10 chromosomes were distinguished unambiguously based on the chromosomal position of repetitive sequences, such as 45S rDNA, 25S rDNA, 5S rDNA, and centromeric repeats. However, this technique can be impractical in that multiple FISHs are required to distinguish these six chromosomes, and it is unable to distinguish the remaining four chromosomes [14,22-25]. Consequently, the BrGSP assigned each of the linkage groups (A1-A10) to the project members as chromosomal substitutes for sequencing [11].

In this study, we developed a second generation $B$. rapa reference linkage map, aligned unambiguously with the cytogenetic map of $B$. rapa. We also used our data to confirm and extend the comparative genome analysis of $B$. rapa and A. thaliana.

\section{Results \\ Construction of the second generation reference linkage genetic map}

Of the 749 SSR motif-containing amplicons designed from 367 sequenced BACs, 311 (41.5\%) showed polymorphism between Chiifu and Kenshin (Additional file 1). Many amplicons designed from Brassica sequences produce multiple bands as a consequence of the extensive genome duplication observed in these species. Anchorage of sequenced BAC clones to linkage maps therefore requires matching of the size of the PCR product from the BAC (derived from Chiifu genomic DNA) with the size of the polymorphic band amplified from genomic DNA (the Chiifu allele). This validation was conducted for all polymorphic markers. The polymorphic PCR product from the genomic DNA was found to match the BAC-derived product for 191 markers (61.4\%), all of which were designed from 188 different BAC clones. There were several instances of the experimentally determined band being greater in size than was expected from the BAC sequences. We attribute these differences to sequencing errors. The 191 BAC-anchoring markers were added to the initial ver- 
sion of the B. rapa linkage map to produce the second generation linkage map (Fig. 1, Fig. 2). This map now anchors 188 sequenced BAC clones to the B. rapa linkage map.

The linkage map contained 719 loci, comprising 267 AFLP, 411 SSR, 24 RAPD, 8 STS, 7 ESTP, and 2 CAPS markers, assigned to the 10 A genome linkage groups (A1A10) of Brassica species following established nomenclature [26]. The total length of the map was $1,123.3 \mathrm{cM}$ with an average distance of $1.6 \mathrm{cM}$ between adjacent loci (Table
1). The length of the linkage groups ranged from $91.3 \mathrm{cM}$ (A10) to $138.5 \mathrm{cM}$ (A06), and the number of markers in the 10 linkage groups ranged from 38 (A4) to 104 (A3). In total, $24.3 \%$ of the markers were mapped at the same loci or at less than $1-\mathrm{cM}$ intervals. The average distance between adjacent loci was greatest for A2 $(2.8 \mathrm{cM})$ and least for A7 $(1.0 \mathrm{cM})$. Two gaps of greater than $10 \mathrm{cM}$ were present (A2), measuring $13.5 \mathrm{cM}$ and $17.7 \mathrm{cM}$, respectively.
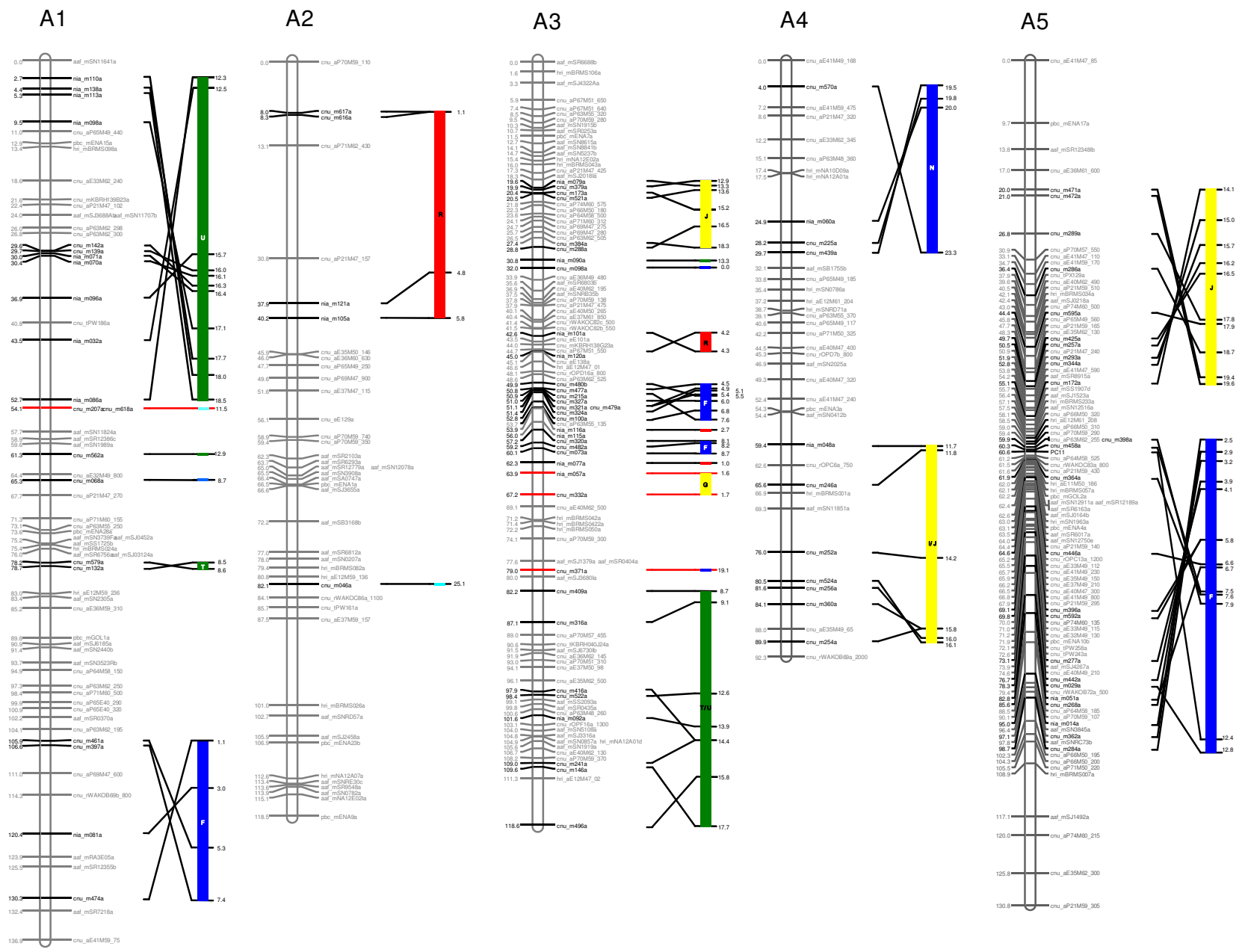

\section{Figure I}

The second generation reference genetic map of $B$. rapa and its alignment onto the Arabidopsis genome sequence (linkage groups AI, A2, A3, A4 and A5). Cumulative recombination distances are shown to the left and marker loci to the right of the linkage groups. SSR markers developed from the BAC sequences are designated in bold strokes. The correspondence between the SSR markers and the BAC clones is given in Additional file 2. The colored bars to the right of the linkage groups indicate Arabidopsis chromosomes (chromosome I: light blue; chromosome 2: yellow; chromosome 3: dark blue; chromosome 4: green; chromosome 5: red), representing the synteny blocks between the two genomes. The synteny blocks identified by Schranz et al. [28] are embedded in the colored bars. New blocks proposed in this study, not identified by Schranz et al. [28], are marked with red lines. The numbers to the right of the colored bars indicate aligned positions on Arabidopsis chromosomes in megabase pairs (Mb). Arabidopsis chromosomes are not to scale. 

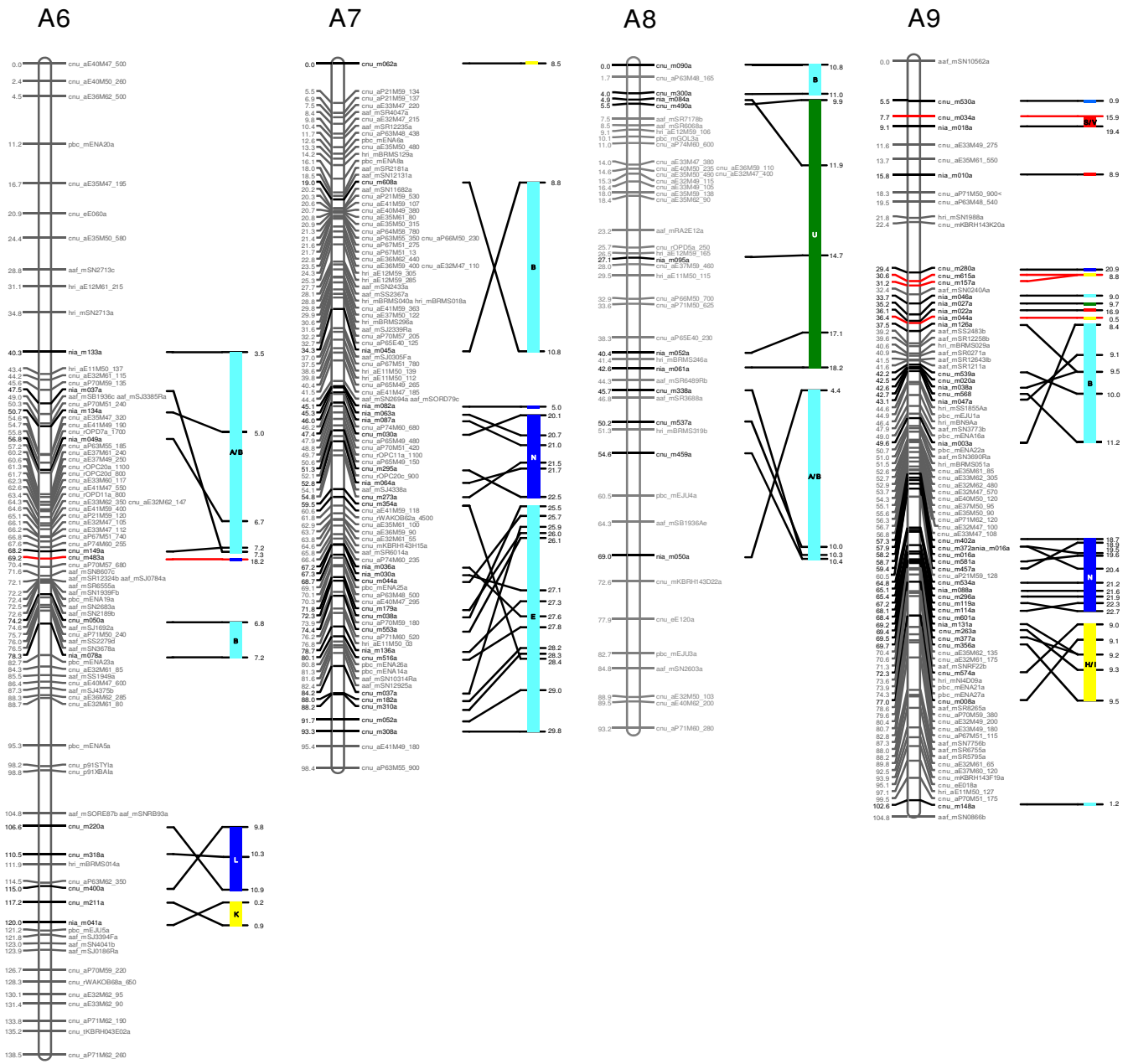

A10

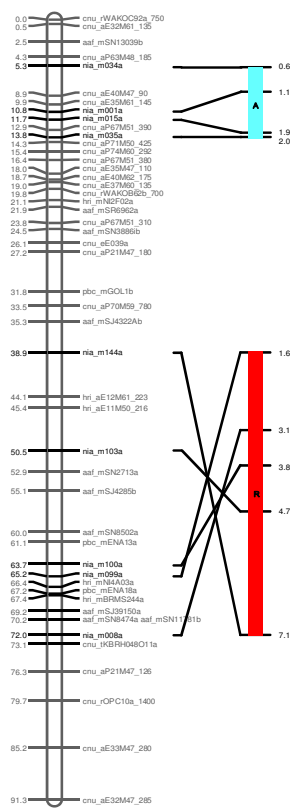

\section{Figure 2}

The second generation reference genetic map of $B$. rapa and its alignment onto the Arabidopsis genome sequence (linkage groups A6, A7, A8, A9 and A10). Cumulative recombination distances are shown to the left and marker loci to the right of the linkage groups. SSR markers developed from the BAC sequences are designated in bold strokes. The correspondence between the SSR markers and the BAC clones is given in Additional file 2. The colored bars to the right of the linkage groups indicate Arabidopsis chromosomes (chromosome I: light blue; chromosome 2: yellow; chromosome 3: dark blue; chromosome 4: green; chromosome 5: red), representing the synteny blocks between the two genomes. The synteny blocks identified by Schranz et al. [28] are embedded in the colored bars. New blocks proposed in this study, not identified by Schranz et al. [28], are marked with red lines. The numbers to the right of the colored bars indicate aligned positions on Arabidopsis chromosomes in megabase pairs (Mb). Arabidopsis chromosomes are not to scale.

\section{Aligning the linkage map with the Arabidopsis genome sequence}

In order to estimate the coverage of the linkage map with respect to the Arabidopsis genome, we aligned the sequences of the anchored BACs to the Arabidopsis genome sequence (Fig. 1, Fig. 2). Of the 188 anchored BAC clones, 184 (representing 187 loci) could be aligned. The aligned regions represent $534.9 \mathrm{cM}$ of the $B$. rapa linkage map and $60.5 \mathrm{Mb}$ of the Arabidopsis genome sequence (Fig. 1, Fig. 2, Table 2, Additional file 2).
We detected 30 blocks of conserved synteny, as defined by two or more adjacent anchored $B$. rapa BACs aligned to the corresponding region of the Arabidopsis genome identified in the earlier maps for A genomes [27,28] (Fig. 1, Fig. 2, Table 3). If the extended positions were detected within our defined blocks of the B. rapa map (Table 3), they were considered extensions of the previously reported blocks (A-X). Blocks G, S, and H (in blocks 9, 25, and 28) were newly identified in the $B$. rapa linkage groups A3, A9, and A9, respectively, compared with the A 
Table I: Salient features of the sequenced BAC anchored second generation reference genetic map of B. rapa

\begin{tabular}{|c|c|c|c|c|c|c|c|}
\hline Linkage group & $\begin{array}{l}\text { No. of total } \\
\text { markers }\end{array}$ & $\begin{array}{c}\text { No. of SSR } \\
\text { markers (\%) }\end{array}$ & $\begin{array}{c}\text { Average } \\
\text { distance } \\
\text { between two } \\
\text { loci (cM) }\end{array}$ & $\begin{array}{l}\text { No. of } \\
\text { anchored } \\
\text { BACs }\end{array}$ & $\begin{array}{l}\text { No. of markers } \\
\text { with I cM } \\
\text { intervals }\end{array}$ & No. of gaps ${ }^{b}$ & Length (cM) \\
\hline Al & 67 & $46(69 \%)$ & 2.0 & 20 & 56 & 0 & 136.9 \\
\hline $\mathrm{A} 2$ & 42 & 27 (64\%) & 2.8 & 4 & 35 & 2 & 118.5 \\
\hline $\mathrm{A} 3$ & 104 & $64(62 \%)$ & I.I & 35 & 80 & 0 & 118.6 \\
\hline A4 & 38 & $21(55 \%)$ & 2.4 & 11 & 36 & 0 & 92.3 \\
\hline A5 & 97 & $50(52 \%)$ & 1.3 & 25 & 64 & 0 & 130.8 \\
\hline A6 & 86 & $40(47 \%)$ & 1.6 & 13 & 68 & 0 & 138.5 \\
\hline A7 & 98 & $49(50 \%)$ & 1.0 & 24 & 64 & 0 & 98.4 \\
\hline $\mathrm{A} 8$ & 47 & $24(5 \mid \%)$ & 2.0 & 11 & 38 & 0 & 93.2 \\
\hline A9 & 91 & 65 (7I\%) & 1.2 & 36 & 60 & 0 & 104.8 \\
\hline AlO & 49 & $25(51 \%)$ & 1.9 & 9 & 43 & 0 & 91.3 \\
\hline Total/avg & 719 & $4 \mid I(57 \%)$ & 1.6 & 188 & $544(76 \%)$ & 2 & $1,123.3$ \\
\hline
\end{tabular}

aAdjacent markers > I cM.

bDistance between adjacent markers $\geq 10 \mathrm{cM}$.

genome map of B. napus $[27,28]$. Blocks $\mathrm{G}$ and $\mathrm{H}$ in the linkage groups of A3 and A9 were recognized in the A genome of B. juncea [29], whereas block S in A9 (in block $25)$ appeared to be unique to the $B$. rapa genome. The longest blocks were 59.9-98.7 cM on A5, aligned to 10.8 $\mathrm{Mb}$ of Arabidopsis chromosome 3, and 2.7-52.7 cM on A1, aligned to $6.2 \mathrm{Mb}$ of Arabidopsis chromosome 4. On aver- age (based on each of the 30 blocks of conserved synteny), we estimate that $1 \mathrm{cM}$ of the $B$. rapa reference genetic map aligns to $341 \mathrm{~kb}$ of the Arabidopsis genome sequence. However, the large standard deviation $(513 \mathrm{~kb})$ indicates that this relationship varies greatly across the aligned genome segments. This alignment updated the initial version of the B. rapa linkage map [16].

Table 2: Summary of the synteny blocks between the B. rapa genetic map and the Arabidopsis genome sequence deduced from BAC alignment

\begin{tabular}{|c|c|c|c|c|c|c|}
\hline $\begin{array}{l}\text { Arabidopsis } \\
\text { chromosome }\end{array}$ & $\begin{array}{l}\text { No. of B. rapa } \\
\text { BACs aligned }\end{array}$ & $\begin{array}{l}\text { B. rapa linkage } \\
\text { groups aligned } \\
\text { (cM) }\end{array}$ & $\begin{array}{l}\text { Total length of } \\
\text { B. rapa linkage } \\
\text { groups aligned }\end{array}$ & $\begin{array}{l}\text { Total length of } \\
\text { Arabidopsis } \\
\text { genome aligned }^{\text {a }}\end{array}$ & $\begin{array}{l}\text { Length of Arabi- } \\
\text { dopsis genome } \\
\text { covered by the } \\
\text { alignment } \\
\text { (\% coverage) }\end{array}$ & $\begin{array}{l}\text { Total length of } \\
\text { Arabidopsis } \\
\text { chromosome }^{b}\end{array}$ \\
\hline 1 & 43 & $\begin{array}{l}\text { A6 (32.0), A7 } \\
(49.1), \text { A8 (27.3), } \\
\text { A9 (12.1), A10 } \\
(8.5)\end{array}$ & $129.0 \mathrm{cM}$ & $21.6 \mathrm{Mb}$ & I $3.7 \mathrm{Mb}(45 \%)$ & $30.4 \mathrm{Mb}$ \\
\hline 2 & 36 & $\begin{array}{l}\text { A3 (12.5), A4 } \\
\text { (30.5), A5 (35.1), } \\
\text { A6 (2.8), A9 (7.9) }\end{array}$ & $88.7 \mathrm{cM}$ & $17.9 \mathrm{Mb}$ & 10.0 Mb (5I\%) & $19.7 \mathrm{Mb}$ \\
\hline 3 & 59 & $\begin{array}{l}\text { Al }(24.4), A 3 \\
(5.7), A 4(25.7), \\
\text { A5 (38.8), A6 } \\
(8.5), \text { A7 (9.6), A9 } \\
(10.9)\end{array}$ & $123.6 \mathrm{cM}$ & $33.4 \mathrm{Mb}$ & $16.9 \mathrm{Mb}(72 \%)$ & $23.5 \mathrm{Mb}$ \\
\hline 4 & 30 & $\begin{array}{l}\text { Al (50.4), A3 } \\
(36.5), A 8(37.7)\end{array}$ & $124.6 \mathrm{cM}$ & $24.2 \mathrm{Mb}$ & $10.1 \mathrm{Mb}(54 \%)$ & $18.6 \mathrm{Mb}$ \\
\hline 5 & 16 & $\begin{array}{l}\text { A2 (32.2), A3 } \\
\text { (2.4), A9 (I.4), } \\
\text { A10 (33.1) }\end{array}$ & $69.1 \mathrm{cM}$ & $14.6 \mathrm{Mb}$ & $9.9 \mathrm{Mb}(37 \%)$ & $27.0 \mathrm{Mb}$ \\
\hline Total & 184 & & 534.9 cM (48\%) & $111.7 \mathrm{Mb}$ & $60.5 \mathrm{Mb}(5 \mathrm{I} \%)$ & $119.2 \mathrm{Mb}$ \\
\hline
\end{tabular}

aDetails of redundantly represented regions in the B. rapa genome are in Table 5.

b[5I] 
Table 3: Summary of the synteny blocks between the B. rapa second generation reference genetic map and the Arabidopsis genome sequence

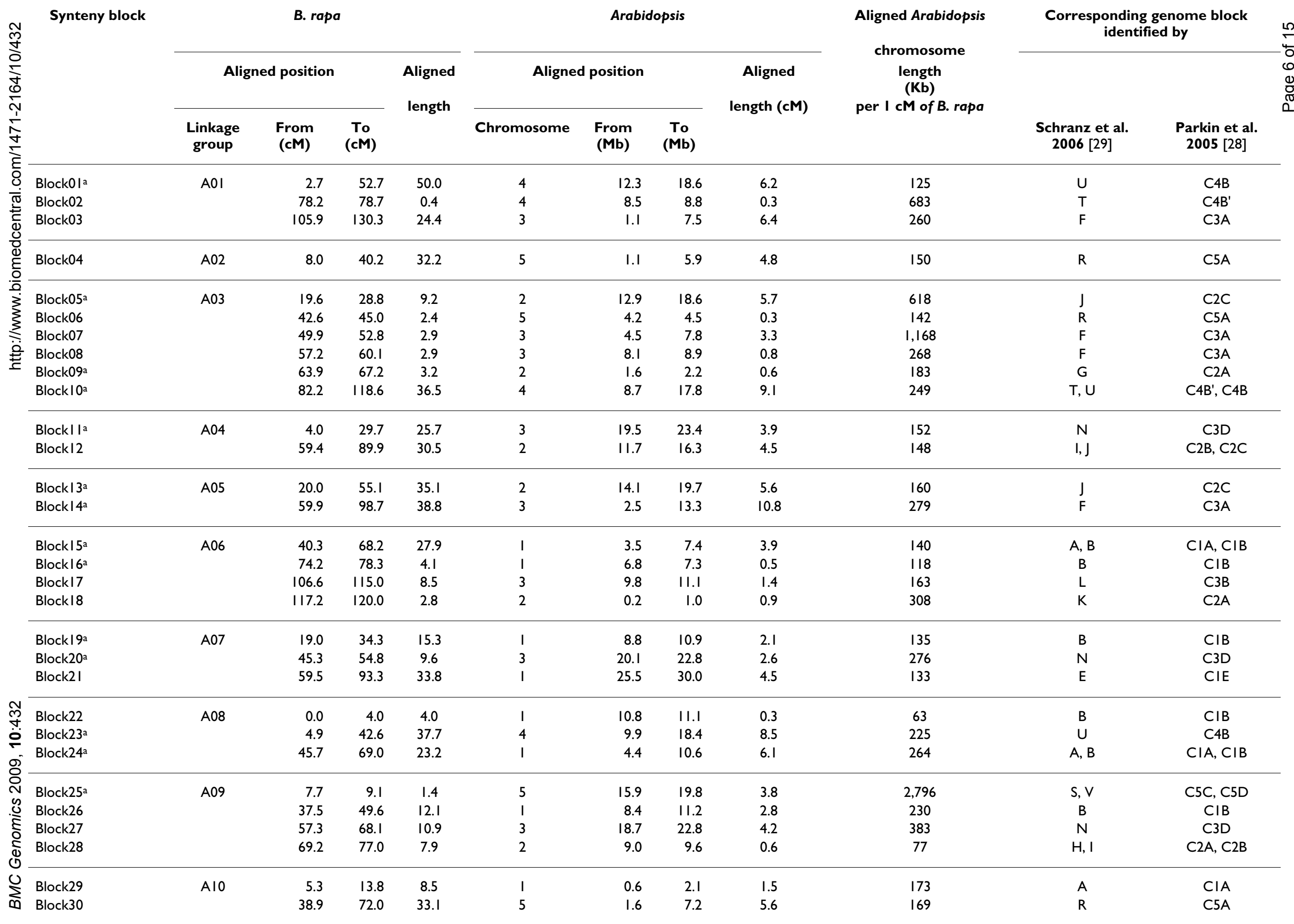

aBlocks expanded compared to the previous reports $[27,28]$ 
Most of the alignments between the linkage map and the Arabidopsis genome sequence were consistent with collinearity blocks previously inferred using sequenced markers with homology to single Arabidopsis genes $[27,28]$. However, we identified the collinear regions for seven additional previously uncharacterized sections of the $\mathrm{A}$ genome by a single aligned $\mathrm{BAC}$, and confirmed three of these by mapping a second marker. The number and ranges of the Arabidopsis gene models for which collinear homologous sequences could be identified were determined by using BAC annotations of the BrGSP [30], and these are shown in Table 4.

Based on the 30 syntenic blocks, we detected 17 and 8 regions that were represented two and three times, respectively, within the $B$. rapa genome (Table 5). All redundantly represented regions were detected between different linkage groups, except one region represented three times, which was identified from two regions in A6 and one in A8 aligned to a 6.8-7.3 Mb region of Arabidopsis chromosome 1 . The total sizes of the regions represented two and three times in the $B$. rapa genome were 18.9 $\mathrm{Mb}$ and $10.8 \mathrm{Mb}$, respectively, based on the sizes of the corresponding Arabidopsis regions. This result indicates that 29.7 Mb of the Arabidopsis genome corresponds to $70.2 \mathrm{Mb}$ of the B. rapa genome. The detected redundant regions were smaller than $3.0 \mathrm{Mb}$ (range: 0.1-3.0 Mb), indicating the scale of the maintained regions after hexapolyploidization. These genetically redundant regions were detected by the same cutoff value of sequence simi- larity, demonstrating that the regions had emerged simultaneously and undergone the same evolutionary events.

\section{Alignment of B. rapa linkage groups and karyotype}

The B. rapa chromosomes are too small and compact to be distinguished by either morphological characteristics or the chromosome arm length ratio. In order to develop markers for complete karyotyping of these chromosomes, BAC clones genetically anchored on our reference genetic map were searched for repetitiveness by sequence similarities or FISH analysis. Consequently, 10 sets of nonrepetitive BAC clones (20 BACs) were selected to distinguish the 10 chromosomes and were fluorescence in situ hybridized on metaphase chromosomes (Table 6). The fluorescence signals of each set of BAC clones (red and green) were detected from each pair of 10 chromosomes (Additional file 3), confirming the utility of BACs in distinguishing the chromosomes. Six chromosomes hybridized by the selected BAC clones from A1, A3, A5, A6, A9, and A10 were recognized to be chromosomes $7,2,4,5,1$, and 10, respectively, based on the following previously reported remarks: (1) the largest chromosome for chromosome 1, (2) the NOR-bearing chromosome for chromosome 2, (3) the 45S rDNA- and CentBr2-hybridized chromosome for chromosome 4, (4) the 45S rDNA-onlyhybridized chromosome for chromosome 5, (5) the 45S rDNA- and 5S rDNA-hybridized chromosome for chromosome 7, and (6) the 5S rDNA-only-hybridized chromosome for chromosome 10 (Additional file 3). The four remaining chromosomes hybridized by BACs from A2,

Table 4: Further enrichment of previously defined collinearity between the Brassica A genome and the Arabidopsis genome

\begin{tabular}{|c|c|c|c|c|c|c|}
\hline Linkage group & Markers & Position (cM) & BAC(s) & AGI range & $\begin{array}{l}\text { No of gene Models } \\
\text { predicted from B. rapa } \\
\text { BAC }\end{array}$ & $\begin{array}{l}\text { No. of Collinear gene } \\
\text { models }\end{array}$ \\
\hline$A I^{a}$ & $\begin{array}{l}\text { cnu_m6/8a } \\
\text { cnu_m207a }\end{array}$ & $\begin{array}{l}54.1 \\
54.1\end{array}$ & $\mathrm{KBrB080J22}$ & At $\lg 51410--A t \lg 51420$ & 27 & 9 \\
\hline$A 3^{b}$ & cnu_m37la & 79.0 & KBrSOI2D09 & At3g5I400--At3g52980 & 27 & 20 \\
\hline$A 3^{a, c}$ & $\begin{array}{l}\text { nia_m057a } \\
\text { cnu_m332a }\end{array}$ & $\begin{array}{l}63.9 \\
67.2\end{array}$ & $\begin{array}{l}\mathrm{KBrB058B} 22 \\
\mathrm{KBrS008CII}\end{array}$ & At2g04540--At2g05755 & 43 & 23 \\
\hline A6b & cnu_m483a & 69.2 & KBrB044DI9 & At3g48950--At3g49210 & 31 & 17 \\
\hline A9c & cnu_m034a & 7.7 & $\mathrm{KBrH} 097 \mathrm{M} 2 \mathrm{I}$ & At5g39760--At5g39880 & 27 & 15 \\
\hline A9a & $\begin{array}{l}\text { cnu_m6I5a } \\
\text { cnu_m } 157 \mathrm{a}\end{array}$ & $\begin{array}{l}30.6 \\
31.2\end{array}$ & $\mathrm{KBrHOI} 4 \mathrm{MO} 07$ & At2g20290--At2g20440 & 13 & 8 \\
\hline A9b & nia_m044a & 36.4 & $\mathrm{KBrB072E02}$ & At2g02 I70--At2g02950 & 20 & 10 \\
\hline
\end{tabular}

aConfirmed by mapping a second marker.

bldentified by a single aligned BAC.

'Belong to our identified blocks. 
Table 5: Summary of the detected regions represented twice or three times in the B. rapa genome based on alignment to Arabidopsis

\begin{tabular}{|c|c|c|c|c|c|}
\hline \multicolumn{3}{|c|}{ Arabidopsis } & \multirow{2}{*}{$\begin{array}{l}\text { Aligned B. rapa } \\
\text { linkage group }\end{array}$} & \multirow{2}{*}{$\begin{array}{l}\text { Frequency in } \\
\text { B. rapa genome }\end{array}$} & \multirow{2}{*}{$\begin{array}{l}\text { Duplicated length in } \\
\text { Arabidopsis genome (Mb) }\end{array}$} \\
\hline Chromosome & Aligned from (Mb) & Aligned to (Mb) & & & \\
\hline \multirow[t]{8}{*}{1} & 4.4 & 6.8 & $A 6, A 8$ & 2 & 2.4 \\
\hline & 6.8 & 7.3 & $A 6, A 6, A 8$ & 3 & 0.5 \\
\hline & 7.3 & 7.4 & $\mathrm{~A} 6, \mathrm{~A} 8$ & 2 & 0.1 \\
\hline & 8.4 & 8.8 & A8, A9 & 2 & 0.4 \\
\hline & 8.8 & 10.6 & A7, A8, A9 & 3 & 1.8 \\
\hline & 10.6 & 10.8 & A7, A9 & 2 & 0.2 \\
\hline & 10.8 & 10.9 & $\mathrm{~A} 7, \mathrm{~A} 8, \mathrm{~A} 9$ & 3 & 0.1 \\
\hline & 10.9 & II.I & A8, A9 & 2 & 0.2 \\
\hline \multirow[t]{3}{*}{2} & 12.9 & 14.1 & $\mathrm{~A} 3, \mathrm{~A} 4$ & 2 & 1.2 \\
\hline & 14.1 & 16.3 & $\mathrm{~A} 3, \mathrm{~A} 4, \mathrm{~A} 5$ & 3 & 2.2 \\
\hline & 16.3 & 18.6 & $\mathrm{~A} 3, \mathrm{~A} 5$ & 2 & 2.3 \\
\hline \multirow[t]{7}{*}{3} & 2.5 & 4.5 & Al, A5 & 2 & 2.0 \\
\hline & 4.5 & 7.5 & $\mathrm{Al}, \mathrm{A} 3, \mathrm{~A} 5$ & 3 & 3.0 \\
\hline & 7.5 & 7.8 & $\mathrm{~A} 3, \mathrm{~A} 5$ & 2 & 0.3 \\
\hline & 8.1 & 8.9 & $\mathrm{~A} 3, \mathrm{~A} 5$ & 2 & 0.8 \\
\hline & 9.8 & 11.1 & $A 5, A 6$ & 2 & 1.3 \\
\hline & 19.5 & 20.1 & $\mathrm{~A} 4, \mathrm{~A} 9$ & 2 & 0.6 \\
\hline & 20.1 & 22.8 & $\mathrm{~A} 4, \mathrm{~A} 7, \mathrm{~A} 9$ & 3 & 2.7 \\
\hline \multirow[t]{4}{*}{4} & 8.7 & 8.8 & AI, A3 & 2 & 0.1 \\
\hline & 9.9 & 12.3 & $\mathrm{~A} 3, \mathrm{~A} 8$ & 2 & 2.4 \\
\hline & 12.3 & 17.8 & $\mathrm{Al}, \mathrm{A} 3, \mathrm{~A} 8$ & 3 & 0.2 \\
\hline & 17.8 & 18.4 & $\mathrm{Al}, \mathrm{A} 8$ & 2 & 0.6 \\
\hline \multirow[t]{3}{*}{5} & 1.6 & 4.2 & $\mathrm{~A} 2, \mathrm{~A} 10$ & 2 & 2.6 \\
\hline & 4.2 & 4.5 & $\mathrm{~A} 2, \mathrm{~A} 3, \mathrm{~A} 10$ & 3 & 0.3 \\
\hline & 4.5 & 5.9 & $\mathrm{~A} 2, \mathrm{~A} 10$ & 2 & 1.4 \\
\hline
\end{tabular}

A4, A7, and A8 were assigned to chromosomes 3, 9, 6, and 8 , respectively. This designation was based solely on the sizes of the four chromosomes, which were numbered from the largest to the smallest in accordance with chromosome morphology [24,31].

The 10 sets of BAC clones distinguishing each chromosome were defined as the definite karyotyping markers for the 10 chromosomes of $B$. rapa. In order to ensure the reliability of the markers, one BAC marker from each of the eight chromosome sets (chr 3-10; chromosomes 1 and 2 are obvious from their morphological remarks), was rehybridized onto one set of B. rapa chromosomes (Fig. 3). Consequently, all eight BACs were hybridized onto individual chromosome pairs, and chromosomes 1 and 2 were recognized by the morphological remarks (the largest chromosome for chromosome 1 and the NOR-bearing chromosome for chromosome 2), thus demonstrating the utility of the developed markers. The current orientations of four linkage groups (A1, A2, A3, A8) [16,27] are incor- rect based on the orientation of chromosomes deduced from FISH signals (Fig. 3), and should be reversed.

\section{Discussion}

The second generation reference genetic map of $B$. rapa A high density linkage map of B. rapa was constructed, resulting in an average marker density of one marker per $1.6 \mathrm{cM}$ and the anchoring of 188 sequenced BAC clones. The SSR markers developed from these BAC sequences were validated by matching the sizes of the Chiifu alleles of the polymorphic band with the PCR product from the corresponding BAC clone. Approximately $57 \%$ of the markers on the map were of the SSR type, which are likely to be transferable to studies involving other Brassica species and populations. Moreover, the 188 sequenced BAC clones anchored on the reference genetic map will serve as a basis for integrating the physical map of $B$. rapa [32] with the reference genetic map.

Anchoring of the sequenced BACs onto the genetic map provided opportunities for aligning the reference map 
Table 6: Assignment of the linkage groups to chromosomes with karyotyping probes and remarks

\begin{tabular}{|c|c|c|c|c|c|}
\hline \multicolumn{4}{|c|}{ Karyotyping markers (BACs) } & \multicolumn{2}{|c|}{ Results } \\
\hline Linkage group & BAC ID & Location (cM) & FISH color & Remarks $^{c}$ & Anchored chromosome \\
\hline \multirow[t]{2}{*}{$\mathrm{Al}$} & $\mathrm{KBrH} 003 \mathrm{F06}$ & 43.5 & red & $45 \mathrm{~S}$ rDNA, $5 \mathrm{~S}$ rDNA & Chr 7 \\
\hline & $\mathrm{KBrH} 003 \mathrm{NI} 8^{\mathrm{b}}$ & 120.4 & green & & \\
\hline \multirow[t]{2}{*}{$\mathrm{A} 2$} & $\mathrm{KBrBO} 3 \mathrm{~N} 08^{\mathrm{b}}$ & 37.9 & red & None & Chr 3 \\
\hline & KBrB005JI7 & 82.1 & green & & \\
\hline \multirow[t]{2}{*}{$\mathrm{A} 3$} & $\mathrm{KBrB} 056108$ & 27.4 & red & Nor-bearing Chromosome & Chr 2 \\
\hline & $\mathrm{KBrSOI2D09}$ & 79.0 & green & & \\
\hline \multirow[t]{2}{*}{ A4 } & $\mathrm{KBrH004D08b}$ & 81.6 & red & None & Chr 9 \\
\hline & KBrB07IMI4 & 4.0 & green & & \\
\hline \multirow[t]{2}{*}{ A5 } & $\mathrm{KBrH003E08b}$ & 95.0 & red & $45 \mathrm{~S}$ rDNA, CentBr2 & Chr 4 \\
\hline & $\mathrm{KBrS004108}$ & 21.0 & green & & \\
\hline \multirow[t]{2}{*}{ A6 } & $\mathrm{KBrB076B03b}$ & 47.5 & red & $45 \mathrm{~S}$ rDNA & Chr 5 \\
\hline & $\mathrm{KBrH009HI5}$ & 117.2 & green & & \\
\hline \multirow[t]{2}{*}{ A7 } & $\mathrm{KBrB084H08}$ & 45.3 & red & None & Chr 6 \\
\hline & $\mathrm{KBrB02IPI5^{ \textrm {b } }}$ & 91.7 & green & & \\
\hline \multirow[t]{2}{*}{ A8 } & $\mathrm{KBrB006AI5^{ \textrm {b } }}$ & 4.9 & red & None & Chr 8 \\
\hline & $\mathrm{KBrH} 005 \mathrm{C} 2 \mathrm{I}$ & 40.4 & green & & \\
\hline \multirow[t]{2}{*}{ A9 } & $\mathrm{KBrHI} 43 \mathrm{FI} \mathrm{a}^{\mathrm{a}}$ & 93.9 & red & The biggest Chromosome & Chr I \\
\hline & $\mathrm{KBrHI} 43 \mathrm{~K} 20^{\mathrm{a}}$ & 22.4 & green & & \\
\hline \multirow[t]{2}{*}{ A10 } & $\mathrm{KBrBO} 2 \mathrm{O} / 3^{\mathrm{b}}$ & 50.5 & red & $5 S$ rDNA & ChrlO \\
\hline & $\mathrm{KBrH053G06}$ & 11.7 & green & & \\
\hline
\end{tabular}

a[16]

bSelected for FISH as in Figure 3.

c [22-24]

onto the Arabidopsis genome sequence on the basis of sequence similarity. Although Arabidopsis and B. rapa diverged approximately 20 million years ago [33], and underwent reshuffling during their respective evolutions, extensive collinearity was maintained between their genomes. On the basis of the 30 blocks of conserved synteny detected in this study, we illustrated possible contractions in the B. rapa genome. For example, in blocks 7 and 25 , we estimated that $1 \mathrm{cM}$ of the $B$. rapa map aligns with 1.2 $\mathrm{Mb}$ and $2.8 \mathrm{Mb}$ of the Arabidopsis genome, respectively. In addition to the identified regions represented twice within the B. rapa genome (Fig. 1, Fig. 2, Table 3), the detected regions represented three times in the genome (Table 5) were similarly divergent in each case in that they were distinguished by the same level of sequence similarity. This supports the hypothesis that proposes the existence of a hexaploid ancestor in the evolution of Brassica species [1-6].

Most of the alignments between the linkage map and the Arabidopsis genome sequence are consistent with previously identified collinearity blocks $[27,28]$. These were initially inferred for $B$. napus using sequenced markers with homology to single Arabidopsis genes [27], and subsequently extended across a number of Brassicaceae [28]. However, our alignments are considerably more robust, as they exploit sequences of whole BAC clones containing homologies to multiple collinear Arabidopsis gene models.
Further, the alleles present in the BAC clones can be matched to the mapped bands in the marker assays. This advantage overcomes the "noise" encountered in comparative genomics as a consequence of homologies to transduplicated gene fragments [6] and enabled us to identify seven previously unreported collinearity blocks. Two of the newly discovered collinearity blocks, represented by BAC clones KBrS008C11/KBrB058B22 and KBrH014M07, correspond to parts of blocks G and H, respectively, of the proposed Brassicaceae ancestral karyotype linkage group AK3 [28]. To date, these have been identified in only a single copy, and these newly discovered copies appear to represent one more of the three proposed paralogs of each that are expected to have arisen as a result of the proposed hexaploidy event in the ancestry of the Brassica species [1-6]. Block K, represented by KBrB072E02, also represents a third copy of the paralogs. Block M, not recognized in the A genome of B. napus [28], was identified. A newly discovered collinearity block represented by BAC clones KBrB080J22, KBrS012D09, and KBrH097M21 correspond to parts of blocks C, N, and S, respectively. These represent the fourth copies of the blocks to be identified, only three copies having being described by Schranz et al. [28]. We interpret the discovery of these blocks as an indication that supernumerary segmental genome duplications, as described for the genomic regions containing the $B$. rapa orthologs of the Arabidopsis gene FLC [5], could be common. Five of these 


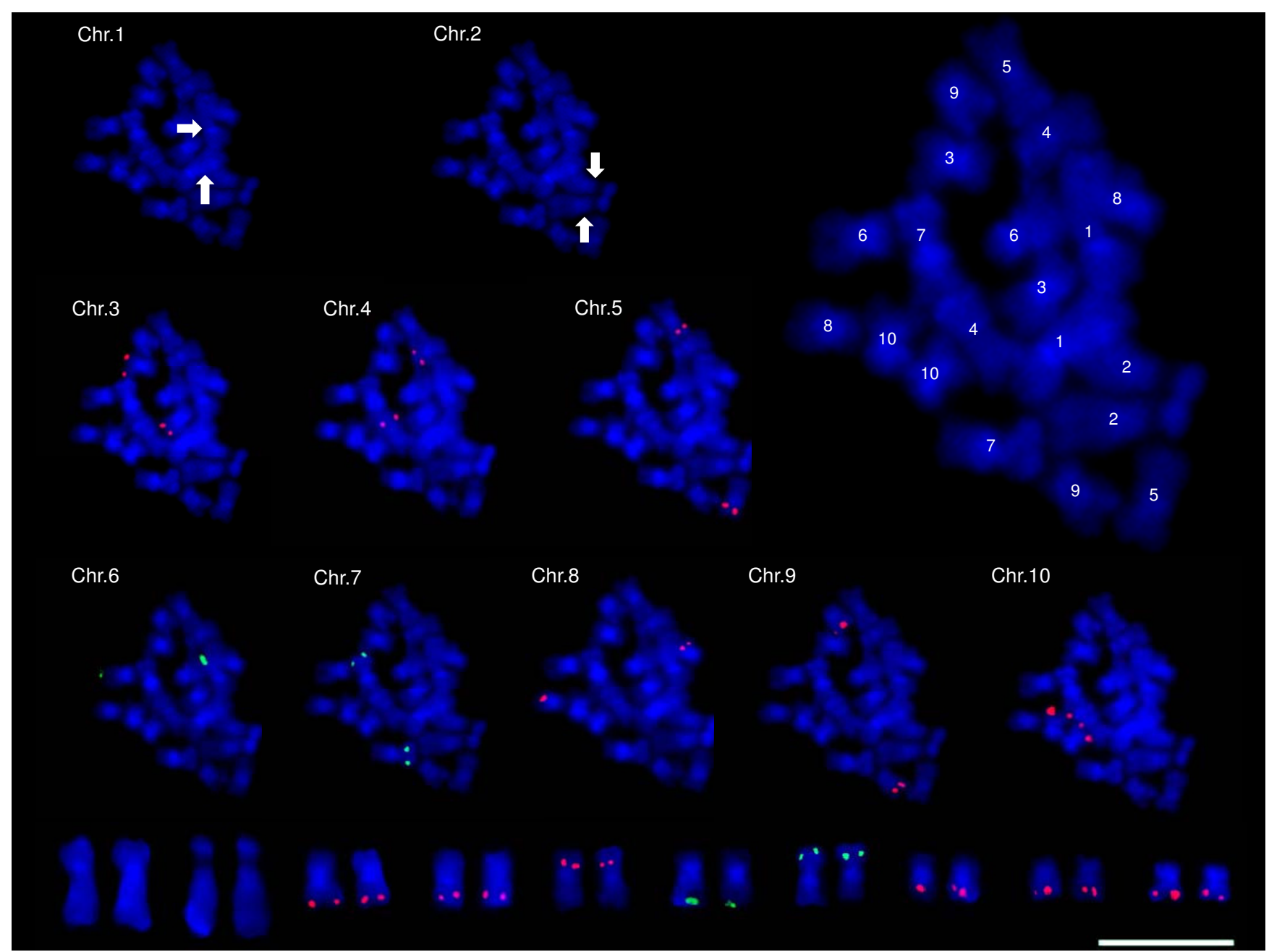

\section{Figure 3}

FISH mapping of one karyotype marker from each of the eight sets on one set of $B$. rapa mitotic metaphase chromosomes. The numbers on the magnified chromosomes represent chromosome numbers. The lowest row shows the karyotype of mitotic metaphase chromosomes with FISH patterns of the karyotype markers. White arrows indicate chromosomes I and 2, which were recognized by the following morphological remarks: the largest chromosome for chromosome I and the NOR-bearing chromosome for chromosome 2. Scale bar $=5 \mu \mathrm{m}$.

blocks (D, G, H, H, and $\mathrm{N}$ ) were recognized in the $A$ genome of B. juncea [29], supporting our new findings.

\section{Integration of the reference genetic map with the 10} chromosomes of $B$. rapa

The twenty BAC clones used in this study were nonrepetitive and genetically anchored, thus allowing integration of the physical and genetic maps with each chromosome. As reported previously, comparative genetic mapping between Arabidopsis and B. rapa has revealed that collinear regions of the genomes are represented two or three times in B. rapa [5,34-36]. Jackson et al. [35] reported multiple duplications of the unique locus on Arabidopsis chromosome 2 ( $79 \mathrm{cM}$ region) in the B. rapa genome by showing
BAC FISH signals from four to six B. rapa chromosomes. In our study, some BACs were located at the loci represented twice (KBrB006A15, KBrB012O13, KBrB013N08, KBrB056I08, KBrB076B03, KBrH003E08, KBrH003N18, $\mathrm{KBrH004D08)} \mathrm{or} \mathrm{three} \mathrm{times} \mathrm{(KBrH003F06,}$ KBrH005C21, KBrB084H08) based on the Arabidopsis alignment data (Fig. 1, Fig. 2, Table 5). However, they were sufficiently divergent, showing unique hybridization and a single BAC FISH signal.

When the BrGSP was launched in 2003, the genome was assigned to participating countries by linkage groups, because at that time the chromosomes were not reconciled with the linkage groups. The previously reported 
karyotyping of $B$. rapa was based on chromosome length, and/or FISH patterns of repetitive DNAs [14,22-25]. From these studies, six chromosomes were distinguished unambiguously based on the chromosomal position of $45 \mathrm{~S}$ rDNA, 25S rDNA, 5S rDNA, and centromeric repeats, whereas the remaining four chromosomes were ambiguous. Fukui et al. [22], Snowdon et al. [23], and Koo et al. [24] designated the recognized chromosomes to chromosomes $1,2,4,5,7$, and 10 in association with chromosomes of the Brassica species, corresponding to chromosomes 1, 2, 5, 4, 3, and 10 of Lim et al. [14,25], respectively. These discrepancies in assigning chromosome numbers are due to the specific characteristics of Brassica chromosomes, which are small and compact, causing different decisions on chromosome length order in the different studies, particularly with metaphase chromosomes. As described earlier, matching chromosomes in different studies in terms of chromosome length is sometimes difficult, and thus emphasizes the importance of the karyotype markers used in this study, which standardize the karyotype. Our chromosome nomenclature is consistent with earlier reports by Fukui et al. [22], and these have been reinforced by Snowdon et al. [23] and Koo et al. [24].

FISH has been used not only for chromosome identification [37] but also for merging genetic, physical, and chromosomal maps [38-42], thereby providing information about genome organization. The first integration of the cytogenetic and genetic linkage maps in Brassica species was achieved in CC genome species by FISH using 22 probes representing 19 loci of nine chromosomes [37]. In the present study, we assigned all 10 linkage groups of the B. rapa reference genetic map to each of the 10 chromosomes and corrected the orientation of the linkage groups by FISH. The 20 cytologically mapped loci will serve as the basis for integration of the genetic, physical, and chromosomal maps of $B$. rapa in the multinational BrGSP.

\section{Conclusion}

We constructed a second generation reference linkage map of $B$. rapa, which has an average marker density of 1 marker per $1.6 \mathrm{cM}$ and to which 188 sequenced BAC clones are anchored. Anchoring of the sequenced BACs onto the reference genetic map provided opportunities for aligning the map onto the Arabidopsis genome sequence on the basis of sequence similarity. We detected 30 blocks of conserved synteny between the B. rapa and Arabidopsis genomes, illustrating rearrangement events with a trace of hexapolyploidy differentiating these genomes. Most of these were consistent with previously reported collinear blocks; however, we were able to identify seven regions as individual BAC clones or a pair of overlapping BAC clones, representing previously unreported collinearity blocks. One of these represents a previously "missing" block under the hypothesis of whole genome triplication, and three of the remaining blocks represent a supernumerary segment under the same hypothesis.

Nonrepetitive and genetically anchored BAC clones allowed integration of the genetic map with the cytogenetic map by developing definite karyotype markers. This is the first unambiguous alignment of the linkage map with the $10 \mathrm{~B}$. rapa chromosomes. We envision that the genetic map and analysis presented here will serve as a basis for integrating the genetic, physical, and chromosomal maps of $B$. rapa in the multinational BrGSP as well as for studies on polyploidization and speciation in the genus Brassica.

\section{Methods \\ SSR marker development}

Five hundred and twenty one sequenced BACs of $B$. rapa ssp. pekinensis generated by the KBGP [12] were collected from GenBank [43]. SSRs were identified from the annotated BACs with SPUTNIK [44] using the parameters described previously by Hong et al. [15]: (i) SSRs were determined to be positive if the repeats were $\geq 12 \mathrm{bp}$ for mononucleotide, dinucleotide, and trinucleotide repeats, $\geq 16 \mathrm{bp}$ for tetranucleotide repeats, and $\geq 20 \mathrm{bp}$ for pentanucleotide repeats; and (ii) no variations (mutations) in repeat motifs were permitted

SSR loci of $\geq 18 \mathrm{bp}$, as described in the preceding, were chosen for marker development. One to three SSR primer sets per BAC were designed using Primer3 software [45] from the flanking sequences of the targeted SSR loci. The primer design criteria were as follows: 100-400 bp of amplicon size, $55-63^{\circ} \mathrm{C}$ of Tm, $>35 \%$ of GC contents, and $>18$ bp of primer length. Totally of 749 primer sets were designed from 367 BAC sequences (Additional file 1). To develop SSR markers, polymorphisms between the parental lines (Chiifu-401-42 and Kenshin-402-43) [16] were evaluated by PCR amplification of the parental genomic DNA using the designed primer sets. PCR products were separated on $6 \%$ polyacrylamide gels and visualized by using a silver staining kit (Bioneer, Daejeon, Korea). Allele matching was performed by analysis of PCR products from genomic DNA of Chiifu-401-42 and the BAC clone from which primers were designed. Mapping was conducted only for markers where the size of the polymorphic band corresponding to the Chiifu allele matched the size of the PCR product from the BAC.

PCR amplification was carried out in $10 \mu \mathrm{l}$ volumes, containing 0.5 units of Taq polymerase (Bioneer, Daejeon, Korea), 5 pmol of each primer, $250 \mu \mathrm{M}$ dNTPs, $2.0 \mathrm{mM}$ $\mathrm{MgCl}_{2}, 1 \times \mathrm{Taq}$ buffer, and $10 \mathrm{ng}$ of genomic template DNA. The PCR profile was as follows: $5 \mathrm{~min}$ at $95^{\circ} \mathrm{C}$, followed by 30-35 cycles with $30 \mathrm{~s}$ of DNA denaturation at 
$94^{\circ} \mathrm{C}$, $30 \mathrm{~s}$ of annealing at the appropriate temperature, and $60 \mathrm{~s}$ of extension at $72{ }^{\circ} \mathrm{C}$, and final extension at $72^{\circ} \mathrm{C}$ for $7 \mathrm{~min}$. PCR was carried out in a Bioneer thermal-cycler (Bioneer, Daejeon, Korea). We followed the locus nomenclature form used in previous reports by Choi et al. [16] which is based on the De Vicente et al. [46] format. The institute codes refer to the laboratory where each primer was screened; those used in this study were 'cnu' for Chungnam National University and 'nia' for the National Institute of Agricultural Biotechnology.

\section{Genetic mapping}

Previously reported plant materials, including two parental inbred lines and a 78-line DH population (CKDH) [16], were used for genetic mapping. Plant genomic DNA was isolated from fresh leaf material according to the procedure used by Guillemaut and Maréchal-Drouard [47].

Markers that were reproducibly polymorphic between parent lines were genotyped in the DH population. Linkage analysis and map construction were performed using JoinMap version $4.0[48,49]$. Linked loci were grouped in the LOD grouping threshold range of 3.8-5.0, and linkage groups were assigned as A1 to A10, corresponding to the previously reported initial version map [16] of this species. Locus order within the LOD grouping was generated for each linkage group using a recombination frequency below 0.45 and an LOD score above 0.5 for all marker pairs within each linkage group. A "ripple" procedure was performed after the addition of each marker and the "jump" thresholds were set to 5. Recombination frequencies were converted to centiMorgans (cM) with Kosambi's method for map-distance calculation [50].

\section{Aligning the linkage map with the Arabidopsis genome sequence}

All 188 sequenced seed BACs [12] anchored to the genetic linkage groups were used for the genome alignment. Repeat sequences in both the B. rapa BACs and the A. thaliana genomic sequences [51] were masked by RepeatMasker [52] and cross-matched [53] with our repeat database collected from the TIGR plant repeat database [54] and Repbase [55]. Each of the B. rapa BACs were aligned to the A. thaliana genome sequence using BLASTZ [56] with parameters of $[\mathrm{B}=0, \mathrm{C}=2, \mathrm{~K}=2200]$. The most highly conserved regions (HCRs) for the alignments between the species were identified by the following criteria: (i) total length of the aligned regions in HCRs between the species should be $\geq 5 \mathrm{~kb}$ and (ii) the number of aligned regions in HCRs should be more than three. To reinforce the method for confirming HCRs between the two species, B. rapa genes in the BAC sequences predicted by GenScan [57] and were compared with A. thaliana genes by BLAST X [58] with a cutoff value of $1 \mathrm{e}-10$.

\section{Chromosome preparation}

Seeds from B. rapa ssp. pekinensis cv. Chiifu-401-42 were germinated on moist filter paper in petridishes at $25^{\circ} \mathrm{C}$ for $48 \mathrm{hr}$. Root tips were sampled and prepared for FISH as previously described by Koo et al. [24] with the following modifications: root tips were excised and incubated in $2 \%$ cellulase (Sigma, St. Louis, USA), 1.5\% macerozyme (Sigma, St. Louis, USA), 0.3\% pectolyase (Sigma, St. Louis, USA), and $1 \mathrm{mM}$ EDTA (pH 4.2).

\section{Fluorescence in situ hybridization probe preparation}

Two BACs from each of the 10 linkage groups (Table 6) were selected as FISH probes to anchor the linkage groups to the chromosomes as well as to distinguish individual chromosomes of B. rapa ssp. pekinensis cv. Chiifu-401-42. The BAC clone, KBrH077I01, containing 176 bp of centromeric tandem repeats, was used as the CentBr2 probe (unpublished data). BAC DNA was extracted by a modified alkaline lysis method [59] with the following changes: BAC clones were cultured for $18 \mathrm{hr}$ in $3 \mathrm{ml}$ of LB media containing $12.5 \mu \mathrm{g} / \mathrm{ml}$ of chloramphenicol and harvested by centrifugation followed by decanting of the media. Cell pellets were resuspended in $200 \mu \mathrm{l}$ of solution I (50 mM Tris $\cdot \mathrm{HCl}, 10 \mathrm{mM}$ EDTA [pH 8.0], $100 \mu \mathrm{g} / \mathrm{ml}$ RNase A) followed by shaking using a vortex. Lysis and neutralization were achieved by adding $200 \mu$ of solution II (0.2 M NaOH, 1\% SDS) and $200 \mu \mathrm{l}$ of solution III (3.0 $\mathrm{M}$ potassium acetate [ $\mathrm{pH} 5.5])$ into the sample plates without a lysis incubation time. The lysates were then cleared and precipitated, followed by $70 \%$ ethanol washing. Each precipitated DNA pellet was re-suspended in 25 $\mu \mathrm{l}$ of $1 \mathrm{mM}$ Tris ( $\mathrm{pH} 8.0$ ). BAC DNAs were labeled with biotin-16-dUTP using nick translation kits (Roche, Basel, Switzerland). The reaction was carried out at $15^{\circ} \mathrm{C}$ for 90 min followed by reaction blocking by the addition of $2 \mu \mathrm{l}$ of $0.5 \mathrm{M}$ EDTA. The reaction products were purified by ethanol precipitation.

The 45S and 5S rDNAs were amplified from the total genomic DNA of $B$. rapa by PCR using the following primer sets: 5'-TACCTGGTTGATCCTGCCAG-3' (forward) and 5'-TTGTCACTACCTCCCCGTGT-3' (reverse) for 45S rDNA [60]; 5'-GATCCCATCAGAACTTC-3' (forward) and 5'-GGTGCTTTAGTGCTGGTAT-3' (reverse) for 5S rDNA [61]. The PCR cycling reaction was carried out in $100 \mu \mathrm{l}$ volumes containing 2.5 units of Taq polymerase (Takara, Kyoto, Japan), 5 pmol of each primer, $250 \mu \mathrm{M}$ dNTPs, $1 \times$ PCR buffer, and $10 \mathrm{ng}$ of genomic template DNA. The amplifying PCR cycle was as follows: 35 cycles with $1 \mathrm{~min}$ of DNA denaturation at $94^{\circ} \mathrm{C}, 1 \mathrm{~min}$ of annealing at $55^{\circ} \mathrm{C}$, and $1 \mathrm{~min}$ of extension at $72^{\circ} \mathrm{C}$, followed by a 10 min final extension at $72^{\circ} \mathrm{C}$. The amplified products were purified using a QIAquick gel extraction kit (Qiagen, Hilden, Germany). Labeling of the 45S and 5S rDNA was performed by a PCR cycling reaction in a $100 \mu$ l volume 
containing 2.5 units of Taq polymerase (Takara, Kyoto, Japan), 5 pmol of primer, $200 \mu \mathrm{M}$ dATP, dCTP, dGTP, 140 $\mu \mathrm{M}$ dTTP, $60 \mu \mathrm{M}$ digoxigenin-dUTP (Roche, Basel, Switzerland), $1 \times$ PCR buffer, and 10 ng of template rDNA. The labeling PCR cycle was identical to the amplifying cycle described previously.

\section{Fluorescence in situ hybridization}

FISH was carried out as described by Koo et al. [24] using $50 \mathrm{ng}$ of labeled probes (BAC DNA, 45S rDNA, 5S rDNA, and CentBr) per slide. Briefly, chromosomal DNA on the slides was denatured with $70 \%$ formamide at $70^{\circ} \mathrm{C}$ for 2 min, followed by dehydration in $70,85,95$, and $100 \%$ ethanol at $-20^{\circ} \mathrm{C}$ for $3 \mathrm{~min}$ each. The probe mixture, containing 50\% formamide $(\mathrm{v} / \mathrm{v}), 10 \%$ dextran sulfate $(\mathrm{w} / \mathrm{v})$, $5 \mathrm{ng} / \mu \mathrm{l}$ salmon sperm DNA, and $500 \mathrm{ng} / \mu \mathrm{l}$ of labeled probe DNA, was denatured at $90^{\circ} \mathrm{C}$ for $10 \mathrm{~min}$ and kept on ice for $5 \mathrm{~min}$. A $20 \mu \mathrm{l}$ volume of the probe mixture was applied to the denatured chromosomal DNA and covered with a glass coverslip. Slides were then hybridized in a humid chamber at $37^{\circ} \mathrm{C}$ for $18 \mathrm{hr}$ followed by standard washing (50\% formamide for $10 \mathrm{~min}$ at $42^{\circ} \mathrm{C}, 2 \times \mathrm{SSC}$ for $5 \mathrm{~min}$ at $42^{\circ} \mathrm{C}$, and $4 \times \mathrm{SSC} / 0.2 \%$ Tween-20 for $5 \mathrm{~min}$ at $42{ }^{\circ} \mathrm{C}$ ) and blocking ( $5 \%$ BSA $/ 4 \times$ SSC/0.2\% Tween-20 for $10 \mathrm{~min}$ at RT). Probes were detected with avidin-FITC and anti-digoxigenin Cy3 (Roche, Basel, Switzerland). Chromosomes were counterstained using $1 \mu \mathrm{g} / \mathrm{ml}$ of DAPI (Vector Lab, Burlingame, USA). The signals were detected with a Cooled CCD Camera, CoolSNAP (Photometrics, Tucson, USA), and images were processed with software (Meta Imaging Series, version 4.6; Molecular Devices, Downingtown, USA) using a Leica epi-fluorescence microscope equipped with FITC-DAPI two-way or FITCRhodamine-DAPI three-way filter sets (Leica, Wetzlar, Gemany). The final printed images were prepared with Adobe Photoshop, version 8.0.

Reprobing wash was performed with $4 \times$ SSC/0.2\% Tween-20 for $30 \mathrm{~min}$ at $37^{\circ} \mathrm{C}$, followed by dehydration in $70,85,95$, and $100 \%$ ethanol at $-20^{\circ} \mathrm{C}$ for 2 min each.

\section{Authors' contributions}

HRK designed the study, carried out the marker development, participated in the FISH analysis, analyzed and interpreted all data, and drafted the manuscript. SRC carried out genetic mapping, participated in the comparative anlaysis, and drafted the manuscript. JB performed the FISH experiment and participated in drafting the manuscript. CPH carried out the SSR analysis, participated in the comparative analysis, and drafted the manuscript. SYL, MJH, DVN, and MJ participated in the marker survey and genotyping. BSP and JWB participated in the design of the study and helped to draft the manuscript. IB participated in the synteny analysis and interpretation of alignment data, and drafted the manuscript. YPL conceived the study, participated in its coordination, and helped to draft the manuscript. All authors read and approved the final manuscript.

\section{Additional material}

\section{Additional file 1}

Details of the 367 BAC sequence derived SSR primers including 191 newly mapped SSR markers.

Click here for file

[http://www.biomedcentral.com/content/supplementary/1471-

2164-10-432-S1.xls]

\section{Additional file 2}

Details of the alignment between the Brassica rapa reference genetic map and the Arabidopsis genome sequence.

Click here for file

[http://www.biomedcentral.com/content/supplementary/14712164-10-432-S2.xls]

\section{Additional file 3}

Fluorescence in situ hybridization (FISH) mapping of 45S rDNA, $5 S$ rDNA, CentBr2, and karyotyping markers (BACs) on the mitotic metaphase chromosomes of Brassica rapa. White arrows indicate the pair of chromosomes hybridized by each set of karyotyping markers (BACs).

$(\mathrm{O})$ and $(\mathrm{X})$ indicate 'hybridized' and 'not hybridized' respectively, on the chromosome pair recognized by each set of karyotyping markers. Scale bar $=5 \mu m$.

Click here for file

[http://www.biomedcentral.com/content/supplementary/14712164-10-432-S3.pdf]

\section{Acknowledgements}

We thank the Korean Brassica Genome Project (KBGP) for providing the 521 seed BAC sequences to the community, and Jing Yue Cai and Da Un Han for technical support. This work was supported by grants from the Technology Development Program for Agricultural and Forestry Ministry of Agriculture, Forestry and Fisheries (grant no. 607002-05), and the Rural Development Administration (BioGreen 2I Program, grant no. 04-I- I2-2), Republic of Korea.

\section{References}

I. O'Neill CM, Bancroft I: Comparative physical mapping of segments of the genome of Brassica oleracea var. alboglabra that are homoeologous to sequenced regions of chromosomes 4 and 5 of Arabidopsis thaliana. Plant J 2000, 23:233-243.

2. Park JY, Koo DH, Hong CP, Lee SJ, Jeon JW, Lee SH, Yun PY, Park BS, Kim HR, Bang JW, Plaha P, Bancroft I, Lim YP: Physical mapping and microsynteny of Brassica rapa ssp. pekinensis genome corresponding to a $\mathbf{2 2 2} \mathrm{kbp}$ gene-rich region of Arabidopsis chromosome 4 and partially duplicated on chromosome 5. Mol Genet Genomics 2005, 274:579-588.

3. Lysak MA, Koch MA, Pecinka A, Schubert I: Chromosome triplication found across the tribe Brassicae. Genome Res 2005, I5:516-525.

4. Rana D, Boogaart T van den, O'Neill CM, Hynes L, Bent E, Macpherson L, Park JY, Lim YP, Bancroft I: Conservation of the microstructure of genome segments in Brassica napus and its diploid relatives. Plant J 2004, 40:725-733.

5. Yang TJ, Kim JS, Kwon SJ, Lim KB, Choi BS, Kim JA, Jin M, Park JY, Lim MH, Kim HI, Lim YP, Kang J], Hong JH, Kim CB, Bhak J, Bancroft I, Park BS: Sequence-level analysis of the diploidization process 
in the triplicated FLOWERING LOCUS C region of Brassica rapa. Plant Cell 2006, I 8:1339-1347.

6. Town CD, Cheung F, Maiti R, Crabtree J, Haas BJ, Wortman JR, Hine EE, Althoff R, Arbogast TS, Tallon LJ, Vigouroux M, Trick M, Bancroft I: Comparative genomics of Brassica oleracea and Arabidopsis thaliana reveal gene loss, fragmentation, and dispersal after polyploidy. Plant Cell 2006, 18:1348-1359.

7. Kowalski SP, Lan TH, Feldmann KA, Paterson AH: Comparative mapping of Arabidopsis thaliana and Brassica oleracea chromosomes reveals islands of conserved organization. Genetics 1994, 138:499-5I0.

8. Paterson AH, Lan TH, Amasino R, Osborn TC, Quiros C: Brassica genomics: a complement to, and early beneficiary of the Arabidopsis sequence. Genome Biol 200I, 2:I-I0II.

9. Quiros CF, Grellet F, Sadowski J, Suzuki T, Li G, Wroblewski T: Arabidopsis and Brassica comparative genomics: sequence, structure and gene content in the ABI-Rps2-CkI chromosomal segment and related regions. Genetics 200I, 157:1321-1330.

10. U N: Genomic anlaysis in Brassica with special reference to the experimental formation of $B$. napus and peculiar mode of fertilization. Japan J Bot 1935, 7:389-452.

11. Lim YP, Plaha P, Choi SR, Um TS, Hong CP, Bang JW, Hur YK: Toward unraveling the structure of Brassica rapa genome. Physiologia Plantarum 2006, I 26:585-59I.

12. Yang TJ, Kim JS, Lim KB, Kwon SJ, Kim JA, Jin M, Park JY, Lim MH, Kim HI, Kim SH, Lim YP, Park BS: The Korea Brassica Genome Project: A glimpse of the Brassica genome based on comparative genome analysis with Arabidopsis. Comp Funct Genom 2005, 6:138-146.

13. Sharing information worldwide for: The Multinational Brassica Genome Project (MBGP) [http://www.brassica.info]

14. Lim KB, Yang TJ, Hwang YJ, Kim JS, Park JY, Kwon SJ, Kim J, Choi BS, Lim MH, Jin M, Kim HI, de Jong H, Bancroft I, Lim Y, Park BS: Characterization of the centromere and peri-centromere retrotransposons in Brassica rapa and their distribution in related Brassica species. Plant J 2007, 49: I73-183.

15. Hong CP, Plaha P, Koo DH, Yang TJ, Choi SR, Lee YK, Uhm T, Bang JW, Edwards D, Bancroft I, Park BS, Lee J, Lim YP: Survey of the Brassica rapa genome by BAC-end sequence analysis and comparison with Arabidopsis thaliana. Mol Cells 2006, 22:300-307.

16. Choi SR, Teakle GR, Plaha P, Kim JH, Allender CJ, Beynon E, Piao ZY, Soengas P, Han TH, King GJ, Barker GC, Hand P, Lydiate DJ, Batley J, Edwards D, Koo DH, Bang JW, Park BS, Lim YP: The reference genetic linkage map for the multinational Brassica rapa genome sequencing project. Theor Appl Genet 2007, i 1 5:777-792.

17. Parkin IA, Sharpe AG, Keith DJ, Lydiate DJ: Identification of the A and $C$ genomes of amphidiploid Brassica napus (oilseed rape). Genome 1995, 38: I I22-II33.

18. Nishibayasahi S: Banding in mitotic chromosomes of Brassica campestris var. pekinensis with a trypsin-Giemsa method. Genome 1992, 35:899-90I.

19. Olin-Fatih M, Heneen WK: C-banded karyotypes of Brassica campestris, B. oleracea, and B. napus. Genome 1992, 35:583-589.

20. Olin-Fatih M: A new method for differential staining of Brassica metaphase chromosomes and karyotypes of $B$. campestris, $B$. olerace a and B. napus. Hereditas 1994, 1 20:253-259.

21. Cheng BK, Heneen WK, Chen BY: Mitotic karyotypes of Brassica campestris and Brassica alboglabra and identification of the $B$. alboglabra chromosome in an addition line. Genome 1995, 38:313-319.

22. Fukui K, Nakayama S, Ohmido N, Yoshiaki H, Yamabe M: Quantitative karyotyping of three diploid Brassica species by imaging methods and localization of 45S rDNA loci on the identified chromosomes. Theor Appl Genet 1998, 96:325-330.

23. Snowdon RJ, Friedrich T, Fried T, Köhler W: Identifying the chromosomes of the A- and C-genome diploid Brassica species B. rapa (syn. campestris) and $B$. oleracea in their amphidiploid $B$. napus. Theor Appl Genet 2002, 104:533-538.

24. Koo DH, Plaha P, Lim YP, Hur Y, Bang JW: A high-resolution karyotype of Brassica rapa ssp. pekinensis revealed by pachytene analysis and multicolor fluorescence in situ hybridization. Theor Appl Genet 2004, 109:1346-1352.
25. Lim KB, de Jong H, Yang TJ, Park JY, Kwon SJ, Kim JS, Lim MH, Kim JA, Jin M, Jin YM, Kim SH, Lim YP, Bang JW, Kim HI, Park BS: Characterization of rDNAs and tandem repeats in heterochromatin of Brassica rapa. Mol Cell 2005, 19:436-444.

26. Suwabe K, Morgan C, Bancroft I: Integration of Brassica A genome genetic linkage map between Brassica napus and $B$. rapa. Genome 2008, 51:169-I76.

27. Parkin IA, Gulden SM, Sharpe AG, Lukens L, Trick M, Osborn TC, Lydiate DJ: Segmental structure of the Brassica napus genome based on comparative analysis with Arabidopsis thaliana. Genetics 2005, 171:765-78I.

28. Schranz ME, Lysak MA, Mitchell-Olds T: The ABC's of comparative genomics in the Brassicaceae : building blocks of crucifer genomes. Trends Plant Sci 2006, I I:535-542.

29. Panjabi P, Jagannath A, Bisht NC, Padmaja KL, Sharma S, Gupta V, Pradhan AK, Pental D: Comparative mapping of Brassica juncea and Arabidopsis thaliana using Intron Polymorphism (IP) markers: homoeologous relationships, diversification and evolution of the A, B and C Brassica genomes. BMC Genomics 2008, 9:II3.

30. Brassica Genome Gateway 2008 [http://brassica.bbsrc.ac.uk]

31. Levan A, Frekga K, Sandberg A: Nomenclature for centromeric position in chromosomes. Hereditas 1964, 52:20I-220.

32. Mun JH, Kwon SJ, Yang TJ, Kim HS, Choi BS, Baek S, Kim JS, Jin M, Kim JA, Lim MH, Lee SI, Kim HI, Kim H, Lim YP, Park BS: The first generation of a BAC-based physical map of Brassica rapa. BMC Genomics 2008, 9:280.

33. Yang YW, Lai KN, Tai PY, Li WH: Rates of nucleotide substitution in angiosperm mitochondrial DNA sequences and dates of divergence between Brassica and other angiosperm lineages. I Mol Evol 1999, 48:597-604.

34. Osborn TC, Kole C, Parkin IA, Sharpe AG, Kuiper M, Lydiate DJ, Trick M: Comparison of flowering time genes in Brassica rapa, B. napus and Arabidopsis thaliana. Genetics 1997, I 46: I I 23-I I 29.

35. Jackson SA, Cheng Z, Wang ML, Goodman HM, Jiang J: Comparative fluorescence in situ hybridization mapping of a $431-\mathbf{k b}$ Arabidopsis thaliana bacterial artificial chromosome contig reveals the role of chromosomal duplications in the expansion of the Brassica rapa genome. Genetics 2000, 156:833-838.

36. Kim JS, Chung TY, King GJ, Jin M, Yang TJ, Jin YM, Kim HI, Park BS: A sequence-tagged linkage map of Brassica rapa. Genetics 2006, 174:29-39.

37. Howell EC, Barker GC, Jones GH, Kearsey MJ, King GJ, Kop EP, Ryder CD, Teakle GR, Vicente JG, Armstrong SJ: Integration of the cytogenetic and genetic linkage maps of Brassica oleracea. Genetics 2002, 16I:1225-1234.

38. Zhong X, Fransz PF, Wennekes-Eden J, Zabel P, Van Kammen A, Hans de Jong J: High-resolution mapping on pachytene chromosomes and extended DNA fibers by fluorescence in-situ hybridization. Plant Mol Biol Rep 1996, 14:232-242.

39. Jackson SA, Wang ML, Goodman HM, Jiang J: Application of fiberFISH in physical mapping of Arabidopsis thaliana. Genome 1998, 41:566-572.

40. Cheng ZK, Presting GG, Buell CR, Wing RA, Jiang J: High-resolution pachytene chromosome mapping of bacterial artificial chromosomes anchored by genetic markers reveals the centromere location and the distribution of genetic recombination along chromosome 10 of rice. Genetics 200I, I57:1749-1757.

4I. Cheung VG, Nowak N, Jang W, Kirsch IR, Zhao S, Chen XN, Furey TS, Kim UJ, Kuo WL, Olivier M, Conroy J, Kasprzyk A, Massa H, Yonescu R, Sait S, Thoreen C, Snijders A, Lemyre E, Bailey JA, Bruzel A, Burrill WD, Clegg SM, Collins S, Dhami P, Friedman C, Han CS, Herrick S, Lee J, Ligon AH, Lowry S, Morley M, Narasimhan S, Osoegawa K, Peng Z, Plajzer-Frick I, Quade BJ, Scott D, Sirotkin K, Thorpe AA, Gray JW, Hudson J, Pinkel D, Ried T, Rowen L, Shen-Ong GL, Strausberg RL, Birney E, Callen DF, Cheng JF, Cox DR, Doggett NA, Carter NP, Eichler EE, Haussler D, Korenberg JR, Morton CC, Albertson D, Schuler G, de Jong PJ, Trask BJ, BAC Resource Consortium: Integration of cytogenetic landmarks into the draft sequence of the human genome. Nature 200I, 409:953-958.

42. Walling JG, Shoemaker R, Young N, Mudge J, Jackson S: Chromosome-level homeology in paleopolyploid soybean (Glycine max) revealed through integration of genetic and chromosome maps. Genetics 2006, I72:1893-1900. 
43. National Center for Biotechnology Information [http:// www.ncbi.nlm.nih.gov]

44. Sputnik [http://www.abajian.com/sputnik]

45. Rozen S, Skaletsky H: Primer3 on the WWW for general users and for biologist programmers. Methods Mol Biol 2000, 132:365-386.

46. De Vicente C, Metz T, Alercia A, Ed: Descriptors for Genetic Markers Technologies: February 2004; Rome Italy: International Plant Genetic Resources Institute; 2004.

47. Guillemaut P, Maréchal-Drouard L: Isolation of plant DNA: A fast, inexpensive, and reliable method. Plant Mol Biol Rep 1992, 10:60-65.

48. Stam P: Construction of integrated genetic linkage maps by means of a new computer package: JoinMap. Plant J 1993, 3:739-744.

49. Van Ooijen JW, Voorrips RE: JoinMap® Version 3.0: Software for the calculation of genetic linkage map Wageningen, The Netherlands, Plant Research International; 200I.

50. Kosambi DD: The estimation of map distance from recombination values. Ann Eugen 1944, 12:172-175.

5I. Haas BJ, Wortman JR, Ronning CM, Hannick LI, Smith RK Jr, Maiti R, Chan AP, Yu C, Farzad M, Wu D, White O, Town CD: Complete reannotation of the Arabidopsis genome: methods, tools, protocols and the final release. BMC Biol 2005, 3:7.

52. RepeatMasker [http://www.repeatmasker.org]

53. Cross-match [http://www.phrap.org]

54. TIGR plant repeat database [http://www.tigr.org/tdb/e2kl/ plant.repeats]

55. Repbase [http://www.girinst.org/repbase]

56. Schwartz S, Kent WJ, Smit A, Zhang Z, Baertsch R, Hardison RC, Haussler D, Miller W: Human-mouse alignments with BLASTZ. Genome Res 2003, 13:103-107.

57. GenScan [http://genes.mit.edu/GENSCAN.html]

58. Altschul SF, Gish W, Miller W, Myers EW, Lipman DJ: Basic local alignment search tool. J Mol Biol 1990, 215:403-4I0.

59. Kim H, San Miguel P, Nelson W, Collura K, Wissotski M, Walling JG Kim JP, Jackson SA, Soderlund C, Wing RA: Comparative physical mapping between Oryza sativa (AA genome type) and $O$. punctata (BB genome type). Genetics 2007, 176:379-390.

60. Nakayama S, Fujishita M, Sone T, Ohyama K: Additional locus of rDNA sequence specific to the $X$ chromosome of the liverwort, Marchantia polymorpha. Chromosome Res 200I, 9:469-473.

61. Koo DH, Hur Y, Jin DC, Bang JW: Karyotype analysis of a Korean cucumber cultivar (Cucumis sativus L. cv. Winter Long) using C-banding and bicolor fluorescence in situ hybridization. $\mathrm{Mol}$ Cells 2002, | 3:4|3-4|8.

Publish with Biomed Central and every scientist can read your work free of charge

"BioMed Central will be the most significant development for disseminating the results of biomedical research in our lifetime. "

Sir Paul Nurse, Cancer Research UK

Your research papers will be:

- available free of charge to the entire biomedical community

- peer reviewed and published immediately upon acceptance

- cited in PubMed and archived on PubMed Central

- yours - you keep the copyright
BioMedcentral 